\title{
Manufacture of a Low Oxalate Mitsumame-Type Dessert Using Rhubarb Juice and Calcium Salts
}

\author{
Sophie Faudon' ${ }^{1}$, Geoffrey Savage ${ }^{2 *}$ \\ ${ }^{1}$ Food Industry, Montpellier SupAgro, Montpellier, France \\ ${ }^{2}$ Food Group, Agriculture and Life Sciences, Lincoln University, Canterbury, New Zealand \\ Email: savage@lincoln.ac.nz
}

Received 20 June 2014; revised 25 July 2014; accepted 8 August 2014

Copyright (C) 2014 by authors and Scientific Research Publishing Inc.

This work is licensed under the Creative Commons Attribution International License (CC BY). http://creativecommons.org/licenses/by/4.0/

c) (i) Open Access

\begin{abstract}
Rhubarb (Rheum rhabarbarum) juice was used to make a Japanese soft mitsumame-type dessert sweet. The dessert was prepared from extracted rhubarb juice, which was cooked with sugar, agar and guar gum, then allowed to set in sweet moulds. The total, soluble and insoluble oxalates were determined in the ingredients and the final products using HPLC chromatography. To reduce the soluble oxalate content of the dessert while retaining the colour and taste of the final product, increments of $\mathrm{CaCl}_{2}$ and $\mathrm{CaCO}_{3}$ were added to the test dessert mixes. The addition of $\mathrm{CaCl}_{2}$ reduced the $\mathrm{pH}$ from $3.55 \pm 0.03$ to $\mathrm{pH} 3.09 \pm 0.02$ while addition of $\mathrm{CaCO}_{3}$ increased the $\mathrm{pH}$ from $3.55 \pm$ 0.03 to $4.96 \pm 0.01$. In both cases, the incremental addition of calcium reduced the soluble oxalate content of the sweets by converting it to insoluble oxalate.
\end{abstract}

\section{Keywords}

Total, Soluble and Insoluble Oxalates, Rhubarb, Mitsumame, Sweets, Calcium

\section{Introduction}

The consumption of foods made from seaweed dates back to Japanese pre-history [1]. Agar, an unbranched polysaccharide derived commercially from the red alga (Gelidium amanssi), has been used in Japanese cuisine for more than 100 years. Mitsumame is a Japanese dessert made from agar and it is usually eaten as small white cubes with pieces of fruit and boiled azuki beans [2]. More recently, different flavours and colours have been added. Japanese people are interested in the development of their traditional foods and they like foods that have delicate flavours and pastel colours. 
Rhubarb (Rheum rhabarbarum) has been cultivated for thousands of years and it grows well in cooler parts of temperate zones throughout the world [3]. While rhubarb stems (petioles) can be eaten raw or cooked, many publications and cookbooks advise that rhubarb should not be consumed regularly as it contains high levels of oxalates [4]. The fleshy petioles of rhubarb are commonly cooked to give the bright red colour in pies, jam and sometimes as the base in wine or as an aperitif [5]. Rhubarb petioles are also cooked as a fruit where they are valued for their unique sharp taste, which comes from the oxalate content. Rhubarb petioles are good sources of vitamins, minerals, dietary fibre and antioxidants [4].

In common with a number of other plants, oxalic acid and its salts occur as end products of the metabolism in leaves and play a central role in a variety of important functions, including tissue calcium regulation, protection from herbivory and metal detoxification [6]. In rhubarb, oxalates are stored in the petioles. The consumption of high oxalate containing foods can increase excretion of oxalate in the urine (oxaluria) which leads to an increased risk of kidney stone formation [7]. Approximately $75 \%$ of all kidney stones are composed of calcium oxalates [8]. The risk of consuming foods high in soluble oxalates has been well documented [7] [9]. This has prompted numerous studies seeking to identify methods to reduce the absorption of soluble oxalates from foods [9] [10]. Reductions in the oxalate concentration in the urine can be achieved by avoiding foods that are known to contain high levels of oxalates [7] and by drinking a higher daily liquid intake to reduce the oxalate concentration of the urine [7] [9]. In addition, soaking and cooking food leads to the loss of soluble oxalates into the cooking water [8] [11] resulting in less oxalate being available for absorption from the digestive tract. Oxalic acid forms water-soluble salts with $\mathrm{Na}^{+}, \mathrm{K}^{+}$and $\mathrm{NH}_{4}{ }^{+}$ions; it can also form insoluble oxalates by binding with $\mathrm{Ca}^{2+}, \mathrm{Fe}^{2+}$ and $\mathrm{Mg}^{2+}$. The consumption of a food containing high levels of calcium [12], the addition of calcium during cooking [13] [14] or the addition of calcium salts during the manufacture of a food are alternative ways to convert soluble oxalates into insoluble oxalates. Insoluble oxalates will not be absorbed in the digestive tract and their formation reduces the bioavailability of oxalate consumed in the diet [14].

The objective of this study was to investigate the manufacture of a mitsumame-type dessert using juice extracted from fresh rhubarb petioles and to investigate a way of reducing the soluble oxalate content in the final products.

\section{Materials and Methods}

\subsection{Sample Preparation}

Three batches of deep frozen $\left(-18^{\circ} \mathrm{C}\right)$, washed and sliced rhubarb (Rheum rhabarbarum) were purchased (Western Harvest, Otaki, Wellington, NZ) in July 2012. Rhubarb juice was extracted using a Juice Fountain, Model BJE200 (Breville Ltd., Manukau, Auckland, NZ). Nine different rhubarb desserts were prepared following the recipe in Table 1; the initial mix contained no added calcium. Four additional mitsumame mixes containing additions of calcium carbonate $\left(99 \% \mathrm{CaCO}_{3} \mathrm{BDH}\right.$ Chemicals, Ltd., Poole, Dorset, UK) and a further four mitsumame mixes containing additions of calcium chloride $\left(78 \% \mathrm{CaCl}_{2}\right.$, Formula Foods Ltd., Christchurch, NZ) were also prepared. Fresh rhubarb juice, white sugar (Chelsea, New Zealand Sugar Company Ltd., Auckland, NZ), agar (Hawkins Watts Ltd., Auckland, NZ), guar gum (Ceres Enterprises Ltd., Auckland, NZ) and an antioxidant/stabilizer mix (E50400, Formula Food Corporation Ltd., Christchurch, NZ) and, apart from the initial mix and the calcium source, these were weighed into a saucepan and heated and stirred at $98^{\circ} \mathrm{C}$ for 6 min. The hot mixture was then poured into small sweet moulds and allowed to set. The sweets were stored at $-18^{\circ} \mathrm{C}$ until analysis could commence.

\section{2. $\mathrm{pH}$ Determination}

The $\mathrm{pH}$ was measured using a SevenEasy $\mathrm{pH}$ Meter (Metler Toledo, GmbH, Schwerzenback, Switzerland). All determinations were performed in triplicate.

\subsection{Extraction of Total and Soluble Oxalic Acid}

The measurement of total and soluble oxalates was performed following the method outlined by Savage et al. [11]. Three replicates of each sweet ( $2.5 \mathrm{~g}$ ) were extracted to measure the total oxalate content and three replicates were extracted to measure the soluble oxalate contents. Forty $\mathrm{mL}$ of $0.2 \mathrm{M} \mathrm{HCl}$ (Aristar, BDH Chemicals, Ltd., Poole, Dorset, UK) were added to flasks for the total oxalate extraction and $40 \mathrm{~mL}$ of Nanopore II water 
Table 1. Weight of each constituent to make mitsumame desserts (g).

\begin{tabular}{cc}
\hline Rhubarb juice & 130 \\
White sugar & 31.3 \\
Agar & 3.3 \\
Guar gum & 0.6 \\
Antioxidant/stabilizer mix & 0.2 \\
\hline
\end{tabular}

(Barnstead International, Dubuque, Iowa, USA, $18 \mathrm{M} \Omega \cdot \mathrm{cm}$ ) were added for the extraction of soluble oxalates. All the flasks were placed in an $80^{\circ} \mathrm{C}$ shaking water bath for $20 \mathrm{~min}$. Subsequently, the solutions were transferred quantitatively into volumetric flasks while still hot. The extracts were then allowed to cool and then made up to $100 \mathrm{~mL}$ with $0.2 \mathrm{M} \mathrm{HCl}$ and Nanopore II water, respectively.

\subsection{Sample Analysis}

The extracts in the volumetric flasks were filtered through a cellulose acetate syringe filter with a pore size of $0.45 \mu \mathrm{m}$ (dismic-25cs, Advantec, California, USA) into a glass HPLC vial. The samples were analyzed with a high performance liquid chromatography (HPLC) system, using a $300 \mathrm{~mm} \times 7.8 \mathrm{~mm}$ Rezex ion exclusion column (Phenomenex Inc., Torrance, CA) attached to a Cation-H guard column (Bio-Rad, Richmond, CA). The equipment consisted of an autosampler (Hitachi AS-2000, Hitachi Ltd., Kyoto, Japan), a Ternary Spectra-Physics SP 8450 (Spectra-Physics, San Jose, CA) set on $210 \mathrm{~nm}$. Data capture was facilitated via a PeakSimple chromatography data system (SRI model 203, SRI Instruments, CA) and data was processed using PeakSimple version 3.93 (SRI Instruments, Torrance, CA). An aqueous solution of $25 \mathrm{mM} \mathrm{H}_{2} \mathrm{SO}_{4}$ (Baker Instra-analyzed reagent, Mallinckrodt Baker, Inc., USA) was used as mobile phase. Samples $(20 \mu \mathrm{L})$ were injected into the column and eluted at a flow rate of $0.6 \mathrm{~mL} / \mathrm{min}$; the column was held at a rate of $0.2 \mathrm{~mL} / \mathrm{min}$ in between the sample sets and equilibrated with a flow rate of $0.6 \mathrm{~mL} / \mathrm{min}$ at least one h prior to use. The oxalic acid peak was identified by comparing the retention time to a standard solution and by spiking the already-filtered sample with a known volume of oxalic acid standard. The insoluble oxalate content of each sample was calculated by the difference between the total and the soluble oxalate content [15]. The amount of calcium bound in the insoluble oxalate fraction was calculated, assuming that it was all calcium oxalate.

\subsection{Standard Calibration}

Two standard curves of oxalic acid (99.99\% oxalic acid, Sigma-Aldrich Co., St. Louis, USA) were prepared and analyzed with standards in the following concentrations: $5 \mathrm{mg} / 100 \mathrm{ml} ; 10 \mathrm{mg} / 100 \mathrm{ml} ; 25 \mathrm{mg} / 100 \mathrm{ml} ; 50 \mathrm{mg} / 100$ $\mathrm{ml} ; 100 \mathrm{mg} / 100 \mathrm{ml}$. One batch of standards was prepared in $0.2 \mathrm{M} \mathrm{HCl}$ while the other one was prepared in Nanopore II water. The acid standard curve was used for identifying and calculating the total oxalate content, while the water standard curve was used for calculating the soluble oxalate content. All blank and standard solutions were filtered through a $0.45 \mu \mathrm{m}$ cellulose nitrate filter (Sartorius, Gottingen, Germany) prior to analysis.

\subsection{Mineral Analysis}

Three replicate samples of each sweet were weighed into a tared microwave vessel and the weight was recorded; then $5 \mathrm{~mL}$ nitric acid (BDH Aristar, BDH Chemicals, Ltd., Poole, Dorset, UK) and $1 \mathrm{~mL}$ of hydrogen peroxide (BDH Aristar, BDH Chemicals, Ltd., Poole, Dorset, UK) was added. The Teflon PFA and Kevlar shielded vessels were then capped and digested using a CEM Mars Express microwave (CEM Corporation, Matthews, North Carolina, USA). The heating programme was as follows: ramp $10 \mathrm{~min}$ to $90^{\circ} \mathrm{C}$; hold for $5 \mathrm{~min}$; ramp for $10 \mathrm{~min}$ to $150^{\circ} \mathrm{C}$; then hold for $5 \mathrm{~min}$. The cooled vessels were uncapped and the solution was dispensed into a $25 \mathrm{ml}$ volumetric flask then made up to the mark with milliQ water. Aristar quality nitric acid and Nanopore II water (Barnstead International, Dubuque, Iowa, USA, $18 \mathrm{M} \Omega \cdot \mathrm{cm}$ ) was used throughout in the digest together with the ICP standards (Varian 720 ICP-OES, Varian Australia Pty Ltd., Melbourne, Australia). ICP standards were Merck multi element or single element standards. The concentration of total calcium in each sample was deter- 
mined in an Inductively Coupled Plasma Optical Emission Spectrophotometer. The sample, in an aerosol form, was introduced into the high energy plasma that dissociated the sample into atoms and ions which emitted electromagnetic radiation. The emitted light was spectrally resolved by diffractive optics and the intensity of light was measured with a detector. There was complete wavelength coverage from $167-785 \mathrm{~nm}$ with a resolution of $7 \mathrm{mg} / \mathrm{kg}$ and all wavelengths were captured in one simultaneous reading.

\subsection{Statistical Analysis}

All calculations were performed using Microsoft Excel version 12. All analyses were carried out in triplicate and the results are presented as a mean $\pm \mathrm{SE}$, with the standard error of the mean.

\section{Results}

The total, soluble and insoluble oxalates (mg/100g FW) of rhubarb juice, agar and guar gum used to make the mitsumame dessert sweets are shown in Table 2. It was also interesting to note that the juice fraction contained appreciable insoluble oxalate content; this is presumably bound in the fine particulate matter suspended in the juice. Analysis of the other ingredients showed that agar and guar gum also contained appreciable amounts of oxalates. Rhubarb juice made up $90.5 \%$ and $94.7 \%$ of the total and soluble oxalate content of the dessert, agar supplied $9.1 \%$ and $5.2 \%$ of the total and soluble oxalate content while guar gum only supplied $0.4 \%$ and $0.1 \%$ of the same constituents. Table 3 shows the $\mathrm{pH}$ and oxalate content of the nine different mitsumame dessert sweets. The mean total oxalate content of the nine different desserts was $476.7 \pm 6.8 \mathrm{mg} / 100 \mathrm{~g}$ WM. The addition of between 66.7 and $170.3 \mathrm{mg}$ calcium/100g WM in the final sweet using, calcium carbonate, increased the $\mathrm{pH}$ from 3.55 to a maximum of 4.96 , while the addition of between 14.5 to $91.9 \mathrm{mg}$ calcium $/ 100 \mathrm{~g} \mathrm{WM}$ in the final sweet, using calcium chloride, decreased the $\mathrm{pH}$ of the final dessert sweet from 3.55 to 3.09. Overall, the addition of these small amounts of calcium during the manufacture of the mitsumame mixes had a considerable effect; increasing the amounts of soluble oxalate that were converted to insoluble oxalate as increments of each calcium salt were added. Addition of $170 \mathrm{mg}$ calcium carbonate/100g sweet was the most efficient way to reduce the soluble oxalate of the final dessert sweet leading to a $95.9 \%$ reduction in soluble oxalate content. The addition of $91.9 \mathrm{mg}$ calcium chloride/100g sweet during the manufacture of the mitsumame dessert reduced the soluble oxalate content by only $75.2 \%$ This, in part, highlights the fact that the same weight of calcium chloride effectively contains a lower calcium content than calcium carbonate. It was also observed that the addition of calcium carbonate made the mitsumame dessert more alkaline while additions of calcium chloride, a Lewis acid, made the mitsumame dessert mix more acid. It was noteworthy that oxalate did not respond stoichiometrically upon the addition of calcium in either case, as not all the added calcium formed insoluble oxalate in the sweet mixture. This may be due to the fact that there are other chelating agents, such as pectin, which may compete with the oxalate for the added calcium.

\section{Discussion}

The oxalate content of the raw rhubarb measured in this study was comparable to previously reviewed data [9] and similar to values for oxalates found in raw rhubarb grown in New Zealand [16]. The oxalate content in raw rhubarb has been well established; however, the levels of oxalate in the juice fraction have not been reported

Table 2. Mean total, soluble and insoluble oxalates (mg/100g FW) \pm SE of rhubarb juice, agar and guar gum used to make the mitsumame dessert sweets, values in brackets are percentage of soluble oxalates of the total oxalate content.

\begin{tabular}{cccc}
\hline & Total oxalate & $\begin{array}{c}\text { Soluble oxalate } \\
\text { (\% soluble of total oxalate) }\end{array}$ & $\begin{array}{c}\text { Insoluble } \\
\text { oxalate }\end{array}$ \\
Raw rhubarb & $726.1 \pm 1.89$ & $414.0 \pm 8.18(57 \%)$ & $551.3 \pm 15.03$ \\
Rhubarb juice & $773.2 \pm 22.91$ & $221.9 \pm 5.94(29 \%)$ & $2599.2 \pm 17.62$ \\
Agar & $3077.5 \pm 39.38$ & $478.3 \pm 21.76(16 \%)$ & $679.0 \pm 22.27$ \\
\hline Guar gum & $749.8 \pm 14.28$ & $70.8 \pm 7.90(9 \%)$ & 6 \\
\hline
\end{tabular}

Values are expressed as mean \pm standard error $(n=3)$. 
Table 3. Oxalate content of the mitsumame dessert mixes with addition of calcium carbonate or calcium chloride (mg/ $100 \mathrm{~g}$ FW of the sweets). Values in brackets are percentage of soluble oxalates of the total oxalate content.

\begin{tabular}{|c|c|c|c|c|c|c|c|c|}
\hline \multirow[t]{3}{*}{$\begin{array}{l}\text { Calcium } \\
\text { salt added }\end{array}$} & \multirow{2}{*}{$\begin{array}{c}\text { Calcium } \\
\text { added } \\
\text { (mg/100g } \\
\text { FW) of sweet }\end{array}$} & \multirow[t]{2}{*}{$\mathrm{pH}$} & $\begin{array}{c}\text { Total } \\
\text { oxalate }\end{array}$ & $\begin{array}{l}\text { Soluble } \\
\text { oxalate }\end{array}$ & $\begin{array}{c}\text { Insoluble } \\
\text { oxalate }\end{array}$ & $\begin{array}{l}\text { Calcium in } \\
\text { insoluble } \\
\text { oxalate }\end{array}$ & \multirow[t]{2}{*}{$\begin{array}{c}\text { Total } \\
\text { calcium }\end{array}$} & \multirow{2}{*}{$\begin{array}{c}\text { Calcium in } \\
\text { insoluble } \\
\text { oxalate/total } \\
\text { calcium }\end{array}$} \\
\hline & & & \multicolumn{4}{|c|}{$(\mathrm{mg} / 100 \mathrm{~g} F W)$} & & \\
\hline & 0 & $3.55 \pm 0.03$ & $509.4 \pm 3.90$ & $321.1 \pm 2.23(63 \%)$ & $188.3 \pm 1.73$ & $18.3 \pm 2.67$ & $18.4 \pm 0.03$ & 99.5 \\
\hline $\mathrm{CaCO}_{3}$ & 66.7 & $3.65 \pm 0.01$ & $474.8 \pm 11.85$ & $138.8 \pm 6.07(29 \%)$ & $335.9 \pm 8.96$ & $32.6 \pm 7.39$ & $85.1 \pm 0.01$ & 38.3 \\
\hline $\mathrm{CaCO}_{3}$ & 93.7 & $4.06 \pm 0.02$ & $445.4 \pm 12.61$ & $52.0 \pm 5.67(12 \%)$ & $393.4 \pm 9.14$ & $38.2 \pm 8.89$ & $112.1 \pm 0.01$ & 34.1 \\
\hline $\mathrm{CaCO}_{3}$ & 124.4 & $4.54 \pm 0.04$ & $462.5 \pm 21.59$ & $22.7 \pm 3.30(5 \%)$ & $439.8 \pm 12.45$ & $42.7 \pm 10.50$ & $142.8 \pm 0.02$ & 29.9 \\
\hline \multirow[t]{2}{*}{$\mathrm{CaCO}_{3}$} & 170.3 & $4.96 \pm 0.01$ & $463.8 \pm 18.38$ & $13.1 \pm 4.89(3 \%)$ & $450.7 \pm 20.13$ & $43.7 \pm 17.52$ & $188.7 \pm 0.02$ & 23.2 \\
\hline & 0 & $3.55 \pm 0.03$ & $509.4 \pm 3.90$ & $321.1 \pm 2.23(63 \%)$ & $188.3 \pm 1.73$ & $18.3 \pm 2.67$ & $18.4 \pm 0.03$ & 99.5 \\
\hline $\mathrm{CaCl}_{2}$ & 14.5 & $3.46 \pm 0.02$ & $464.9 \pm 2.52$ & $251.9 \pm 6.45(54 \%)$ & $245.9 \pm 3.85$ & $23.9 \pm 2.50$ & $33.3 \pm 0.04$ & 71.8 \\
\hline $\mathrm{CaCl}_{2}$ & 41.4 & $3.32 \pm 0.01$ & $501.9 \pm 8.94$ & $196.7 \pm 8.72(39 \%)$ & $305.2 \pm 0.27$ & $29.6 \pm 2.41$ & $60.2 \pm 0.01$ & 49.2 \\
\hline $\mathrm{CaCl}_{2}$ & 82.5 & $3.23 \pm 0.01$ & $487.4 \pm 8.96$ & $156.7 \pm 3.17(32 \%)$ & $330.7 \pm 12.28$ & $32.1 \pm 9.83$ & $101.3 \pm 0.01$ & 31.7 \\
\hline $\mathrm{CaCl}_{2}$ & 91.9 & $3.09 \pm 0.02$ & $480.3 \pm 6.51$ & $79.6 \pm 9.62(17 \%)$ & $400.7 \pm 3.09$ & $38.9 \pm 4.01$ & $110.7 \pm 0.01$ & 35.1 \\
\hline
\end{tabular}

Values are expressed as mean \pm standard error $(n=3)$.

previously in cooked rhubarb. Boiling is the most effective method to reduce soluble oxalate in foods especially if the cooking water is discarded [8] [11]. Depending on the cooking method used, the amount of oxalates and the ratio of soluble to total oxalate remaining in cooked food may vary. Earlier studies [16] showed that the soluble oxalate contents of rhubarb could be significantly reduced (49\% reduction) when the petioles were cooked in water, while cooking with standard or trim milk reduced the soluble oxalate content by a further $65.9 \%$ and 74.5\%, respectively. This result confirmed a number of earlier studies which showed that addition of calcium containing foods during cooking of a number of different moderate to high oxalate containing foods led to a significant reduction of soluble oxalate in the cooked food [12]-[14]. However, in this study the rhubarb juice was heated at $98^{\circ} \mathrm{C}$ for 6 min with the other ingredients and no leaching losses were possible. There have been no studies to investigate the addition of permitted food additives, such as calcium carbonate and calcium chloride, which contain much higher levels of calcium than added milk or yoghurt. This would be a more efficient way to reduce the soluble oxalate content of a food during manufacture and cooking.

The effectiveness of the addition of small amounts of calcium chloride and calcium carbonate during the preparation of the mitsumame dessert can be seen in Table 3. The reduction of the soluble oxalate content and the consequent rise in the insoluble oxalate content is highlighted by the incremental addition of the two different calcium sources. The effectiveness of calcium carbonate addition can be partially explained by its higher calcium ion content compared to calcium chloride. The addition of calcium carbonate had a significant effect on the $\mathrm{pH}$ of the mitsumane dessert making it more alkaline and this would have the effect of increasing the proportion of the $\mathrm{C}_{2} \mathrm{O}_{4}^{2-}$ oxalate species which can then bind to free calcium. A significant $(\mathrm{p}<0.05)$ polynomial relationship between the calculated amount of calcium in the insoluble oxalate fraction and the addition of calcium from calcium carbonate was $\mathrm{y}=0.170 \mathrm{x}^{2}-260+28.4, \mathrm{R}^{2}=0.954$. Addition of increments of calcium chloride had the effect of increasing the acidity of the mitsumame dessert which increased the proportion of the $\mathrm{HC}_{2} \mathrm{O}_{4}^{-}$species present and this was less efficient at binding to free calcium. A significant $(\mathrm{p}<0.05)$ linear relationship between the insoluble oxalate fraction and the addition of calcium from calcium chloride was $\mathrm{y}=4.92 \mathrm{x}-$ 94.46, $\mathrm{R}^{2}=0.912$. The proportions and the relationships of the three possible species of oxalate $\mathrm{H}_{2} \mathrm{C}_{2} \mathrm{O}_{4}$, $\mathrm{HC}_{2} \mathrm{O}_{4}^{-}$and $\mathrm{C}_{2} \mathrm{O}_{4}^{2-}$ to the $\mathrm{pH}$ of an ideal aqueous medium have been discussed previously by Simpson et al. [12] and the form of these relationships were confirmed by the data obtained in this experiment.

In terms of human nutrition it is important to confirm that the insoluble oxalate, which is mainly calcium oxalate, is not absorbed in the small intestine. Calcium oxalate is not soluble at the mean pH 8.5 of the small in- 
testine but soluble oxalate will be available for absorption through the mucosa [17]. The speciation diagram [12] shows that conversion of insoluble oxalate to soluble oxalate will not occur at the mean $\mathrm{pH} 8.5$ of the intestine.

\section{Conclusion}

This is the first time that juice extracted from rhubarb petioles has been used to colour and flavour mitsumametype desserts. The overall taste and colour were appreciated in informal tastings. The texture and appearance of the mitsumame sweets made in this study were similar to traditionally prepared mitsumame sweets but the main issue was an attempt to reduce the soluble oxalate content of the dessert sweets without compromising the taste and colour of the product. Chemical analysis showed that this could be achieved by the addition of relatively small amounts of calcium from mineral sources during the manufacture of the sweets. Overall, the soluble oxalate content of the dessert sweets made in this study would not pose any health problems from the soluble oxalate content as dessert sweets are only consumed in very small amounts at the end of special meals. Further experiments are required to evaluate the taste, colour and storage characteristics of this new product.

\section{Acknowledgements}

The authors wish to acknowledge Leo Vanhanen for his help throughout the experiment and Janette Busch for proof reading the text.

\section{References}

[1] Nisizawa, K.H., Noda, H., Kikuchi, R. and Watanabe, T. (1987) The Main Seaweeds in Japan. Hydrobiologia, 151/152, 5-29. http://dx.doi.org/10.1007/BF00046102

[2] Hagoromo Foods (2005) Pacific Research Consulting New Canned Dessert Foods from Hagoromo Foods. Hagoromo Foods, Tokyo.

[3] Clementi, E.M. and Misiti, F. (2010) Potential Health Benefits of Rhubarb. Ch. 27. In: Ronald Ross, W. and Victor, R.P., Eds., Bioactive Foods in Promoting Health, Academic Press, San Diego, 407-423.

[4] Blundstone, H.A.W. and Dickinson, D. (1964) The Chemistry of Edible Rhubarb. Journal of the Science of Food and Agriculture, 15, 94-101. http://dx.doi.org/10.1002/jsfa.2740150205

[5] Chin, T.C. and Youngken, H.W. (1947) The Cytotaxonomy of Rheum. American Journal of Botany, 34, 401-407. http://dx.doi.org/10.2307/2437150

[6] Nakata, P.A. (2003) Advances in Our Understanding of Calcium Oxalate Crystal Formation and Function in Plants. Plant Science, 164, 901-909. http://dx.doi.org/10.1016/S0168-9452(03)00120-1

[7] Massey, L.K. (2003) Dietary Influences on Urinary Oxalate and Risk of Kidney Stones. Frontiers in Bioscience, 8, s584-594. http://dx.doi.org/10.2741/1082

[8] Chai, W.W. and Liebman, M. (2005) Effect of Different Cooking Methods on Vegetable Oxalate Content. Journal of Agricultural and Food Chemistry, 53, 3027-3030. http://dx.doi.org/10.1021/jf048128d

[9] Noonan, S.C. and Savage, G.P. (1999) Oxalate Content of Foods and Its Effect on Humans. Asia Pacific Journal of Clinical Nutrition, 8, 64-74. http://dx.doi.org/10.1046/j.1440-6047.1999.00038.x

[10] Liebman, M. and Al-Wahsh, I.A. (2011) Probiotics and Other Key Determinants of Dietary Oxalate Absorption. Advances in Nutrition, 2, 254-260. http://dx.doi.org/10.3945/an.111.000414

[11] Savage, G.P., Vanhanen, L., Mason, S.M. and Ross, A.B. (2000) Effect of Cooking on the Soluble and Insoluble Oxalate Content of Some New Zealand Foods. Journal of Food Composition and Analysis, 13, 201-206. http://dx.doi.org/10.1006/jfca.2000.0879

[12] Simpson, T.S., Savage, G.P., Sherlock, R. and Vanhanen, L.P. (2009) Oxalate Content of Silver Beet Leaves (Beta vulgaris var. cicla) at Different Stages of Maturation and the Effect of Cooking with Different Milk Sources. Journal of Agricultural and Food Chemistry, 57, 10804-10808. http://dx.doi.org/10.1021/jf902124w

[13] Brogren, M. and Savage, G.P. (2003) Bioavailability of Soluble Oxalate from Spinach Eaten with and without Milk Products. Asia Pacific Journal of Clinical Nutrition, 12, 219-224.

[14] Oscarsson, K.V. and Savage, G.P. (2007) Composition and Availability of Soluble and Insoluble Oxalates in Raw and Cooked Taro (Colocasia esculenta var. Scott) Leaves. Food Chemistry, 101, 559-562. http://dx.doi.org/10.1016/j.foodchem.2006.02.014

[15] Holloway, W.D., Argall, M.E., Jealous, W.T., Lee, J.A. and Bradbury, J.H. (1989) Organic Acids and Calcium Oxalate in Tropical Root Crops. Journal of Agricultural Food Chemistry, 37, 337-341. http://dx.doi.org/10.1021/jf00086a014 
[16] Nguyen, H.H.V. and Savage, G.P. (2013) Oxalate Availability in Raw and Cooked Rhubarb. Proceedings of the Nutrition Society of New Zealand, 35, 20-24.

[17] Savage, G.P. and Catherwood, D.J. (2007) Determination of Oxalates in Japanese Taro Corms Using an in Vitro Digestion Assay. Food Chemistry, 105, 383-388. http://dx.doi.org/10.1016/j.foodchem.2006.12.023 
Scientific Research Publishing (SCIRP) is one of the largest Open Access journal publishers. It is currently publishing more than 200 open access, online, peer-reviewed journals covering a wide range of academic disciplines. SCIRP serves the worldwide academic communities and contributes to the progress and application of science with its publication.

Other selected journals from SCIRP are listed as below. Submit your manuscript to us via either submit@scirp.org or Online Submission Portal.
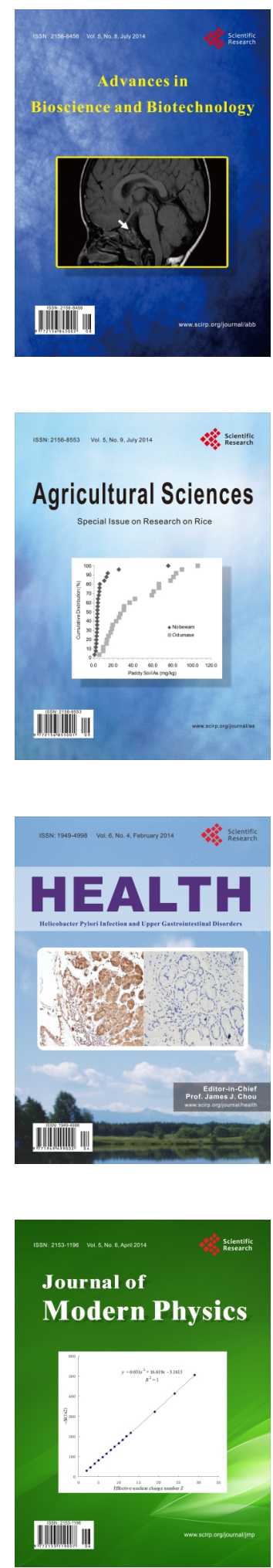
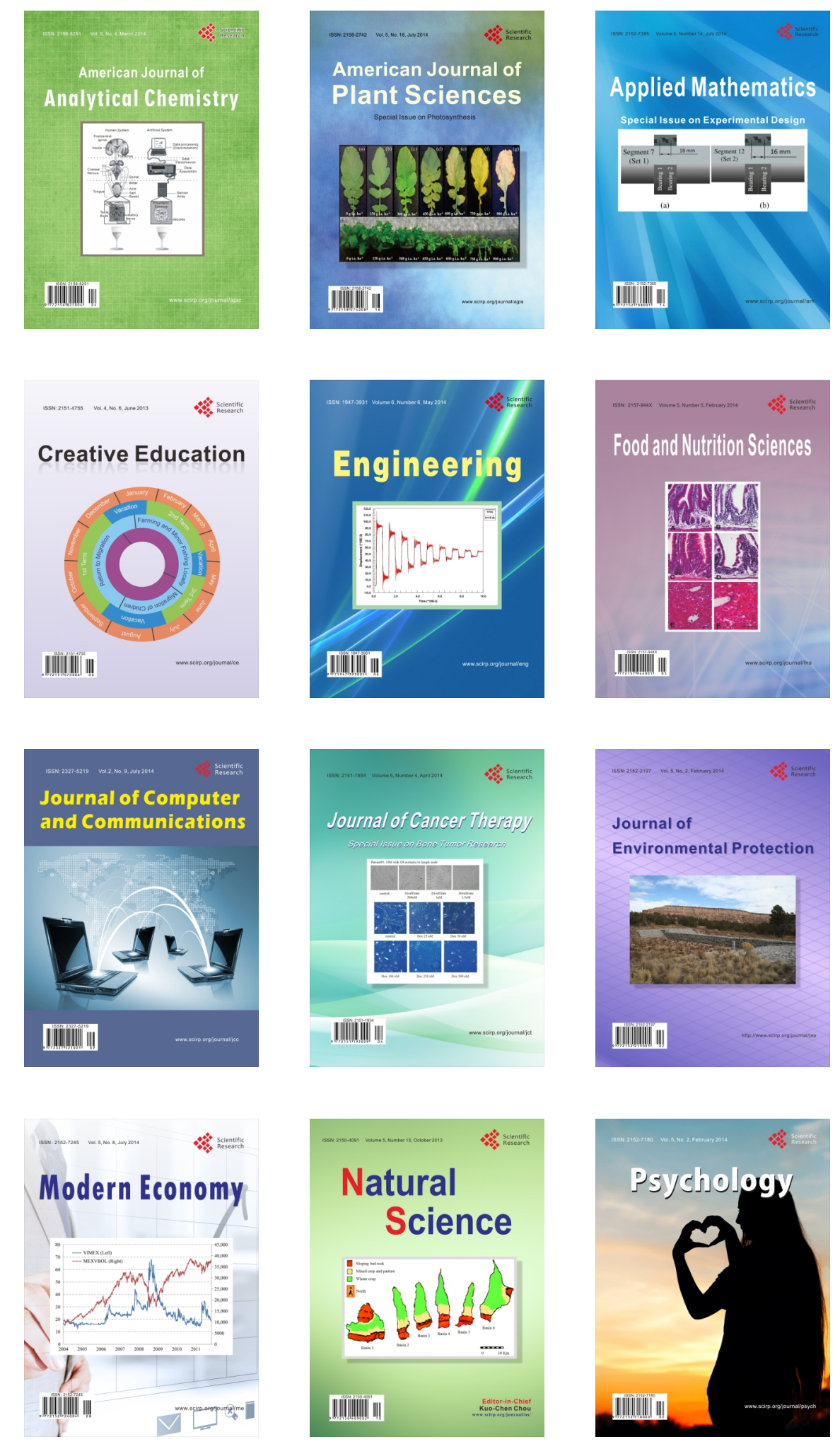